University of Tennessee Health Science Center UTHSC Digital Commons

Summer 8-12-2021

\title{
Integrating Digital Health Technology to Alleviate Caregiver Burden
}

Patricia Ann Hunt

University of Tennessee Health Science Center

Follow this and additional works at: https://dc.uthsc.edu/hiimappliedresearch

Part of the Health and Medical Administration Commons

\section{Recommended Citation}

Hunt, Patricia Ann, "Integrating Digital Health Technology to Alleviate Caregiver Burden" (2021). Applied Research Projects. 77. . https://doi.org/10.21007/chp.hiim.0074

https://dc.uthsc.edu/hiimappliedresearch/77

This Research Project is brought to you for free and open access by the Department of Health Informatics and Information Management at UTHSC Digital Commons. It has been accepted for inclusion in Applied Research Projects by an authorized administrator of UTHSC Digital Commons. For more information, please contact jwelch30@uthsc.edu. 
Integrating Digital Health Technology to Alleviate Caregiver Burden

\author{
Patricia Hunt \\ University of Tennessee Health Science Center \\ Master of Health Informatics and Information Management \\ Advisor: Dr. Rebecca Reynolds \\ IRB \# 21-08252-XM
}

August 2021 
This is dedicated to my mom, dad, aunt, and grandmother who I was most proud to serve.

You are my inspiration.

May you rest in peace. 


\begin{abstract}
The elder population in our country is growing at an exponential pace. Studies have shown that elders who are aged 80 years and older are projected to suffer from age related issues such as Alzheimer's, dementia, and osteoporosis and will need assistance with Long Term Services and Support (LTSS). Additionally, many elders are also projected to suffer from more severe chronic illnesses such as diabetes, cancer, and heart related illnesses. Because many of these elders are aging in place, residing in their own homes, they will require the services of at home assistance, which high probability will be a neighbor, friend, or family member, serving in the role as an informal caregiver. As the pace of elders increasingly outnumbers informal caregivers, strategic methods must be evaluated, researched, and implemented to ensure caregivers are not becoming overwhelmed and contributing to our chronic health population due to caregiver burden, and to also ensure informal caregivers have the appropriate level of holistic support (emotionally, physically, financially, and spiritually) needed to provide adequate care to our aging population. This paper will focus on the emergence of digital health technology and how it can be beneficial to informal caregivers and care recipients.
\end{abstract}




\section{Table of Contents}

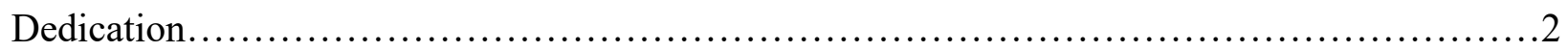

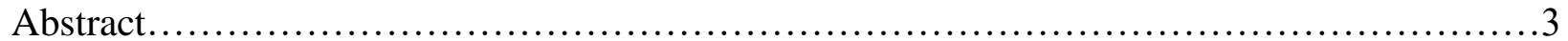

Table of Contents................................................................4

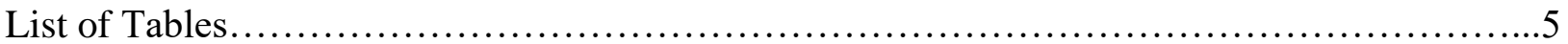

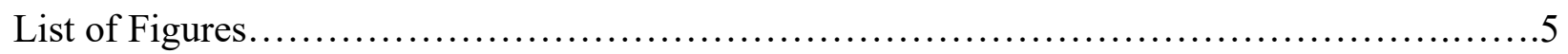

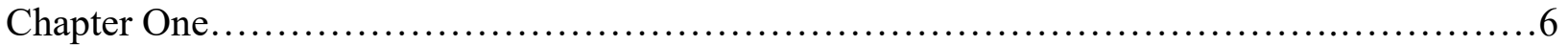

Introduction............................................................6

Background of Problem...................................................... 10

Purpose of Study........................................................ 16

Research Objectives...................................................... 18

Limitations........................................................... 18

Definition of Terms........................................................ 19

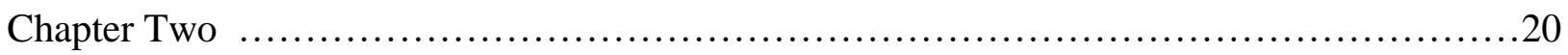

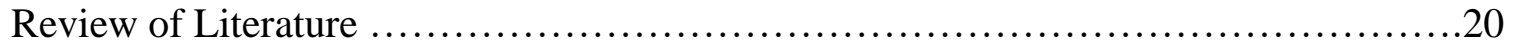

Results..............................................................20

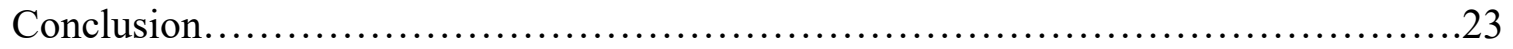

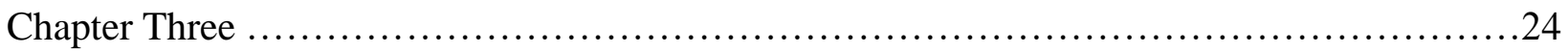

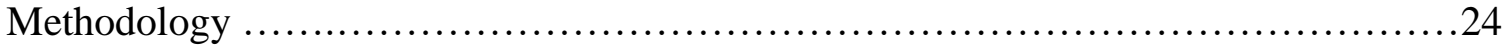

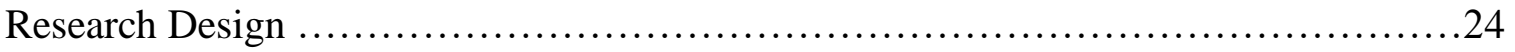

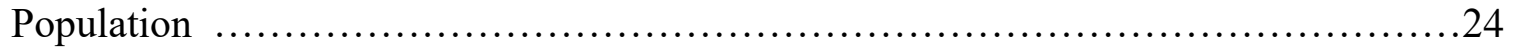

Data Analysis..........................................................24

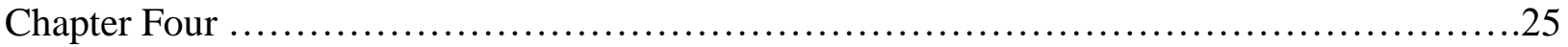

Results.................................................................... 25

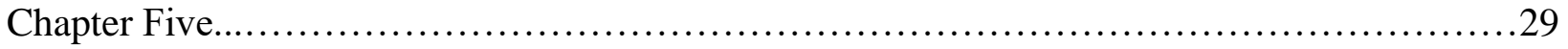

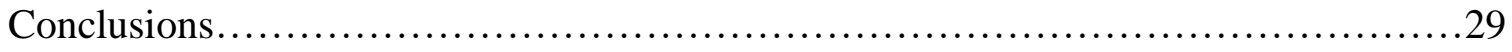

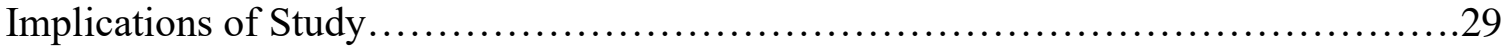

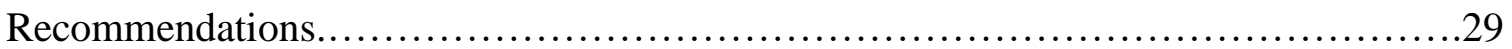

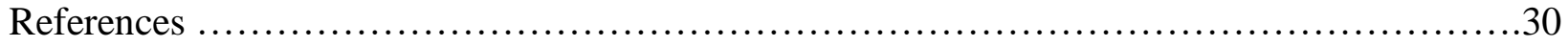




\section{Tables}

Table 1 - Chronic Conditions from Centers for Medicare and Medicaid Services (CMS)........7

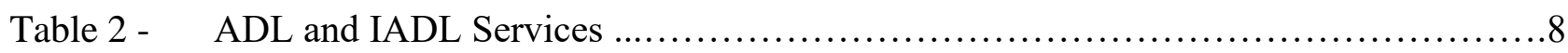

\section{List of Figures}

Figure 1 - 2017 Medicare Beneficiaries Chronic Conditions Category..........................7

Figure 2 - Telomere Length In Caregivers........................................... 12

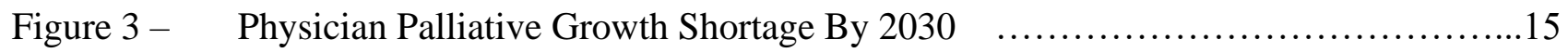

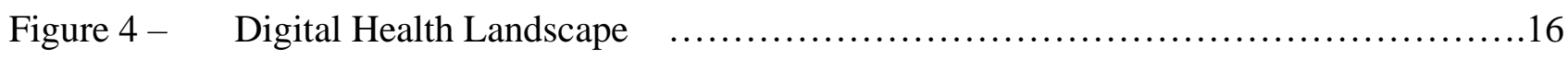

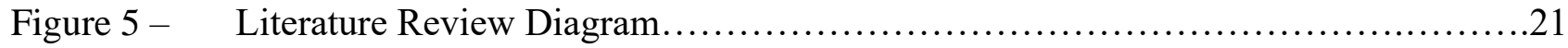

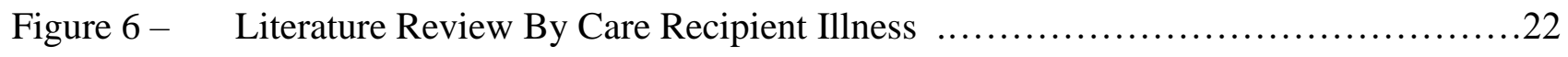

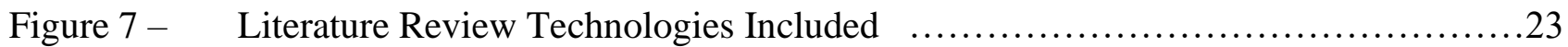

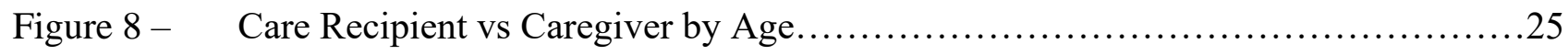

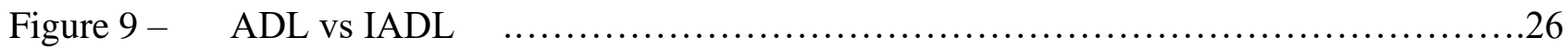

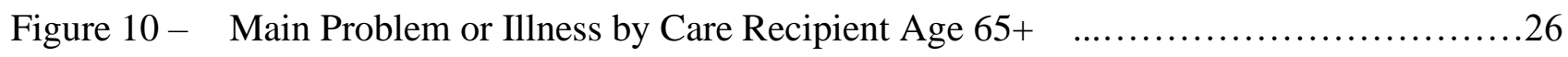

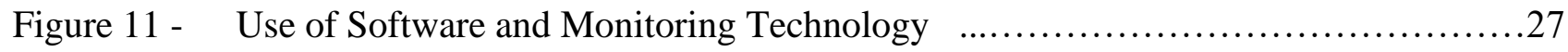

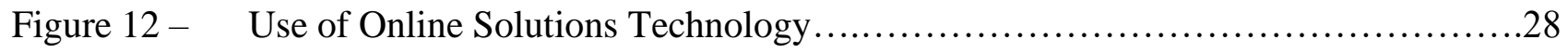

Figure 13 - Online and Software Monitoring Usage by Age..............................28 


\section{Chapter 1 - Introduction \\ Care Recipient}

The number of individuals turning 65 years of age continues to grow daily at an exponential pace of approximately 10,000 individuals a day (AARP, 2019). By the year 2030, in North America, it is projected individuals aged 65 years or older will exceed over 71 million people (CDC, 2019b) and worldwide that number will exceed approximately 1 billion senior citizens (Roberts et al., 2018). 65 years of age is a milestone age in our society as it marks when one qualifies for Medicare, the federal health insurance program for senior citizens. As many seniors are living longer, they are opting to age in place by remaining in the familiar comforts of their own homes in lieu of transitioning to a nursing home or assisted living facility. Aging in place is defined as one's ability to remain in their own homes living safely, comfortably, and independently (CDC, 2009a). Allowing senior citizens to remain in their homes as they age has many physical and emotional benefits. For example, remaining in a familiar environment allowing them to feel safe lessens their anxiety about having to learn new surroundings. Remaining in their own homes also allows them to continue their existing social connections with their community combating depression and social isolation. Lastly, aging in place allows elders to remain distant from potential outbreaks that may exist in structured facilities, as evidenced with the outbreak of COVID-19 in nursing homes. Although potential benefits do exist, aging in place can also have disadvantages. For example, as seniors continue to age, it is highly probable they will be afflicted by one or more chronic health conditions becoming high risk patients requiring more specialized coordinated care. Below are chronic conditions per the Centers for Medicare and Medicaid Chronic Conditions dashboard. 


\begin{tabular}{|l|l|}
\hline Alcohol Abuse & Drug Abuse/ Substance Abuse \\
\hline Alzheimer's Disease and Related Dementia & Heart Failure \\
\hline Arthritis (Osteoarthritis and Rheumatoid) & Hepatitis (Chronic Viral B \& C) \\
\hline Asthma & HIV/AIDS \\
\hline Atrial Fibrillation & Hyperlipidemia (High cholesterol) \\
\hline Autism Spectrum Disorders & Hypertension (High blood pressure) \\
\hline Cancer (Breast, Colorectal, Lung and Prostate) & Ischemic Heart Disease \\
\hline Chronic Kidney Disease & Osteoporosis \\
\hline Chronic Obstructive Pulmonary Disease & Schizophrenia and Other Psychotic Disorders \\
\hline Depression & Stroke \\
\hline Diabetes & \\
\hline
\end{tabular}

Table 1 Chronic Conditions from Centers for Medicare and Medicaid Chronic Dashboard (CMS.gov, 2021b)

Managing our seniors with chronic conditions can be extremely costly. In 2017, approximately 46 million Medicare beneficiaries had at least one chronic condition and Medicare spending totaled 20 percent of total healthcare spending at 706 billion dollars (CMS.gov, 2018a). Additionally, 15 percent of total Medicare beneficiaries had 6 or more chronic conditions with a per capita Medicare spending of \$27,968 dollars.

Figure 1 Medicare Fee For Service (FFS) Beneficiaries with at least 1 chronic condition

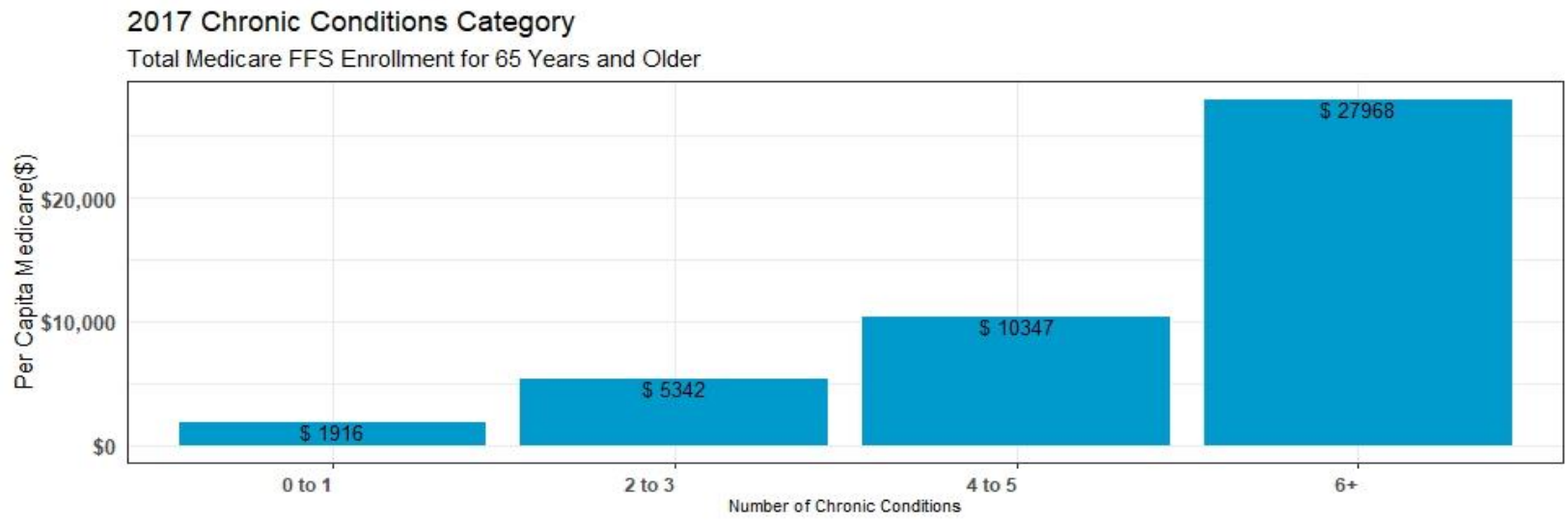


Additionally, aging seniors often require assistance with Activities of Daily Living (ADLs) and/or Instrumental Activities of Daily Living (IADLs) tasks. ADL tasks are basic self-care tasks the care recipient needs to have a level of independence. IADL tasks are more complex tasks the care recipient needs to have a level of independence in addition to a functional quality of life. As seniors age, they inevitably transition from a state of independence to a state of care recipient, requiring the support of another individual or facility to assist with their myriad of needs in order to maintain independent living status. Individuals who take on the role of assisting care recipients are caregivers. "The shift in health care to community-based settings rather than traditional residential care settings puts additional pressure on families to fill the gaps in Long Term Services \& Support (LTSS). Caregivers increasingly provide and monitor complex care at home, navigating the care system, advocating for their care recipient, and paying for services to help the person with care needs" (NAC \& AARP, 2020). Because of the profound number of projected senior citizens who may require assistance with ADL and IADL services, as well as chronic health care management, it is important to understand the significance of the role of the caregiver.

\begin{tabular}{|l|}
\hline Activities of Daily Living (ADL) - \\
Basic essential self care tasks \\
necessary for independent living. \\
Examples: \\
: Walking \\
- Bathing \\
- Dressing \\
- Grooming \\
- Trileting \\
- Eansferring \\
\hline
\end{tabular}

Instrumental Activities of Daily
Living (IADL) - More complex tasks
necessary for independent living.
Examples:
- Shopping
- - Maning
- Managing Medications
- Housework / Laundry
- Mansportation
- Managing Finances

Table 2 ADL and IADL Services 


\section{Caregiver}

According to the CDC (2019), caregivers are defined as someone who provides continued care and assistance to a care recipient on a regular basis. Caregivers can be further categorized as formal or informal. Formal or paid caregivers are professional caregivers who serve in a caregiving capacity, having received formal training to perform such tasks and are financially compensated for their services. Formal caregivers can provide physical and/or mental care services to their patients. Examples of formal caregivers are doctors, nurses, physicians, social workers, psychologists, and therapist. Informal or unpaid caregivers are individuals who provide continued care to care recipients but are not financially compensated for their services. Informal caregivers often times have not received adequate training in advance to care for care recipients but are sometimes required to provide complex care such as wound care. Lastly, informal caregivers most often have a personal relationship with the care recipient, such as a neighbor, friend, or family member. As stated by Reinhard, "We know that family caregivers provide help with activities such as bathing and dressing, shopping, cooking and preparing meals. We also ask caregivers to do things that would make even nursing students tremble; it's important that we understand the scope of this new normal " (Reinhard, n.d. ).

The care recipient's need for assistance may vary from recipient to recipient and can often change as time progresses; therefore, caregivers must be compassionate, empathetic, understanding, patient, observant, organized and innovative, flexible, and agile in their caregiving approach. Because caregivers provide a wide range of complex services, often for prolonged periods of time, the question is often asked, "Who is caring for the caregiver?" For example, physician burnout is recognized in doctors who have been exposed to long term stress from demanding work pace, time sensitive pressures and prolonged intense emotional involvement. Physician burnout can impact memory, attention to detail and the ability to 
properly function, which can be detrimental to the care recipients safety and quality of care (AHRQ, 2017). Formal and informal caregivers are both hugely important in providing cohesive and holistic care to the care recipient; however, this paper will focus on the role of the informal caregiver.

\section{Background of Problem}

\section{Caregiver Burden}

According to Valuing the Invaluable 2019 Update, as of 2017 approximately 41 million caregivers (informal) in the US provided 34 billion hours of care to adults estimating their unpaid contribution to over $\$ 470$ billion dollars (Reinhard et al., 2019). Additionally, the Caregiving in the US 2020 report states, “... family caregivers - whether they be families of kin or families of choice - are woven into the fabric of America's health, social, economic, and longterm services and supports (LTSS) systems. As the country continues to age, the need to support caregivers as the cornerstone of society will only become more and more important" (NAC \& AARP, 2020). Informal caregivers are often called the "invisible workforce" because they provide an invaluable service but often times in the shadows of our healthcare ecosystem. Informal caregivers more often experience caregiver burden. Liu et al. (2020) conducted a literature review of 33 articles and defines the term caregiver burden as the immense burden a person carries while providing care for someone who is chronically ill, disabled or elderly affecting both the caregiver and care recipient. According to the CDC (2019), "Informal or unpaid caregivers (family members or friends) are the backbone of long-term care provided in people's homes. While some aspects of caregiving may be rewarding, caregivers can also be at increased risk for negative health consequences. These may include stress, depression, difficulty maintaining a healthy lifestyle, and staying up to date on recommended clinical preventive services". The BMC Health Services Research Organization conducted a national caregiving 
survey of 3026 US adults. Per the survey responses, the BMC (Slaboda et al., 2021) concluded the physical and emotional effects of caregiver burden can have long term negative implications on the caregiver's health as well as the care they provide to the care recipient. BMC also states the caregiving role can range from assistance with self-care and ADL services to assisting with complicated medical needs such as managing medication, coordinating health care, and caring for patient wounds. Because family caregivers are often supporting and attending to the needs of the care recipient, they often times forfeit the need to care for themselves leaving family caregivers to experience physical, emotional, and economic hardship due to caregiver burden. Researchers are becoming more cognitive regarding monitoring stress levels of caregivers to determine the long-term effects on chronic illnesses and the caregiver's health and also on the caregiver's ability to provide quality and safe care to our aging seniors. For example, one study conducted determined a correlation between caregivers and shortened telomeres. Telomeres are a significant part of our DNA and play a huge role in how our cells age. Studies have shown caregivers in some instances, such as primary caregivers to Alzheimer's patients, endure a significant amount of emotional and psychological stress, having shortened telomeres in comparison to non-caregivers, possibly accelerating the aging process and shortening their life span (Damjanovic et al., 2007). According to Nobel winning molecular biologist and researcher Elizabeth Blackburn, "Telomere shortening has been linked to increased risk of cardiovascular disease, cancer, diabetes and Alzheimer's - the diseases that many of us eventually die of" (Barnett, 2017) . Dr. Gabor Mate (2013), states one study showed telomeres were ten years shorter than the chronological age of mothers who cared for chronically ill children indicating the chronic stress of caregiving aged them by ten years. Mate further states the way caregivers provide care and the support system they have in place while providing care can hugely impact the caregiver's health. 
Figure 2 Telomere Length in Caregivers Accelerated telomere erosion is associated with a declining immune function of caregivers of Alzheimer's disease patients (Damjanovic et al., 2007)

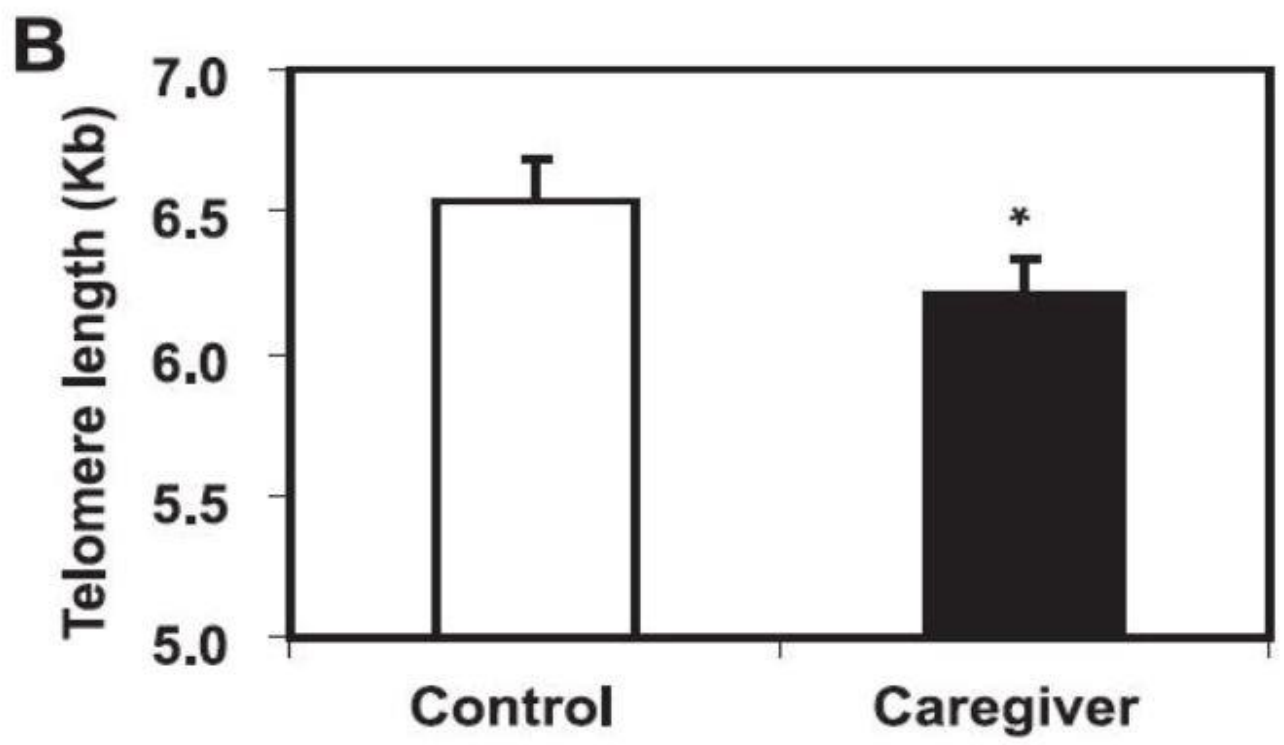

In addition to stressors caregivers may receive from caregiving duties, studies are being conducted to see if caregivers are also receiving additional stressors from social determinants of health $(\mathrm{SDOH}) . \mathrm{SDOH}$ are environmental conditions that can affect life outcomes such as, where people are born, live, learn, work, play, worship, and age. These factors can have a wide range of effects on health, functioning and quality of life (AHRQ, 2017). Because SDOH stressors can further exacerbate a caregiver's health, having a clear understanding of how SDOH stressors impact caregivers can assist clinicians with recommending adequate resources and can also assist policy makers with implementing policies regarding caregivers health-related quality of life (HRQOL) (Turnage, n.d.). Per Heath (2020), patients who do not have their basic needs covered such as insurance coverage, adequate transportation, or a safe place to live might have poorer heart failure outcomes. Heath further states the American Heart Association (AHA) has placed a call to action against the medical community to include social determinants of health $(\mathrm{SDOH})$ and family caregiver needs during heart failure treatment and management. Young 
states, “...most caregivers experience emotional strain, but the particular sources of strain may vary according to such factors as the care recipient's condition and the demographic characteristics and social determinants of health for both the care recipient and the caregivers" (Young et al., 2020).

\section{Caregiver Assessment}

As our health system is already fragmented and strained, the services informal caregivers provide to our aging population is extremely significant. Because of this, understanding and accommodating the needs of caregivers is essential not only to ensuring caregivers have the support and infrastructure they need to care for themselves and their recipients, but also to ensure they are not contributors to our chronic high risk health population. The Zarit Burden Interview (ZBI), originally developed in 1980 as a 29-item questionnaire, is widely recognized by aging agencies as a credible means to determine if a caregiver is suffering from caregiver burden (APA, 2020). The current ZBI version has been modified to only include 12 items; however, according to Gratao et al. (2019), "The ZBI 12 can be considered valid for evaluation of burden in clinical practice and research as a fast, efficient option for screening burden among older caregivers of community dwelling older adults". Although the ZBI is an accepted tool to access whether a caregiver is suffering from caregiver burden, administering it is not mandated.

Currently, capturing and accessing the needs of the caregivers on a global scale is not standardized at the federal level. Per Kelly et al. (2013), "Family support is often essential for helping older people and adults with disabilities continue to live at home and in the community. Yet, the work of family caregivers can be demanding-physically, emotionally, and financially. If caregiver needs are not assessed and addressed, their own health and well-being may be at risk, which may, in turn, lead to burnout_-jeopardizing their ability to continue providing care in the community". The National Family Caregiver Support Program (NCFSP) is a federal 
program created in 2000 under the Older Americans Act to focus on the needs of family caregivers. Per Feinberg (2019), "A key area in which the NFCSP can be more effective is by making family caregiver assessments a standard practice. The outcome evaluation found that Area Agencies on Aging (AAAs) that examined the impact of caregiving in their assessment process were effective at targeting the family caregivers with the greatest caregiver burden". The importance of including caregiver assessment during physician visits is also being highlighted as an area where caregiver needs can be assessed and adequately documented. Per Spigelmeyer (2019), informal caregivers are also called co-providers as they provide care that was previously performed by nurses before healthcare shifted from institutional to community based care. Spigelmeyer further states healthcare providers should access the well-being of care recipients as well as caregivers of adults during healthcare visits. This can be beneficial for the care recipient, caregiver, and the provider. The caregiver can provide invaluable information and insight to the provider regarding the care recipient for adequate care planning. The provider can assess the caregiver and collect data that can identify at risk caregivers preempting adverse outcomes. The care recipient can directly benefit from their primary caregiver receiving adequate care.

\section{Caregiver Shortage}

A potential caregiving shortage is looming. As the older population continues to increase, so does the demand for informal caregiving services; however, families are actually decreasing in size creating a void in the number of family members to serve in the informal caregiving role. According to Redfoot et al. (2013), "the supply of family caregivers is unlike to keep pace with future demand". Because of this, the US is projected to experience a severe family caregiver shortage. The Caregiver Support Ratio is defined as the number of potential informal caregivers between the ages of 45-64 in ratio to elders aged 80 or more categorized as high-risk elders more 
likely to require long-term care. Statistics show 7 potential caregivers currently exists per adult in the high-risk age range of 80 years or older. However, by 2030 this number is expected to significantly decrease to 4 potential caregivers per older adult in the high-risk category. In addition to a projected informal caregiver shortage, there is also an anticipated Palliative Physician Growth Shortage. Palliative care is defined as medical care provided by specialized physicians and nurses to help people with serious illnesses manage symptoms providing relief and a quality of life (getpalliativecare.org, 2021). As our seniors age and begin to experience more chronic conditions, they are expected to also need more palliative care; however, the palliative care physician workforce is drastically decreasing as well. By 2030, the projected ratio of palliative care physician to every patient requiring palliative care is 1 to 26,000 (Kamil et al., 2017)

Figure 3 Physician Palliative Growth Shortage By 2030 (Slaboda et al., 2021)

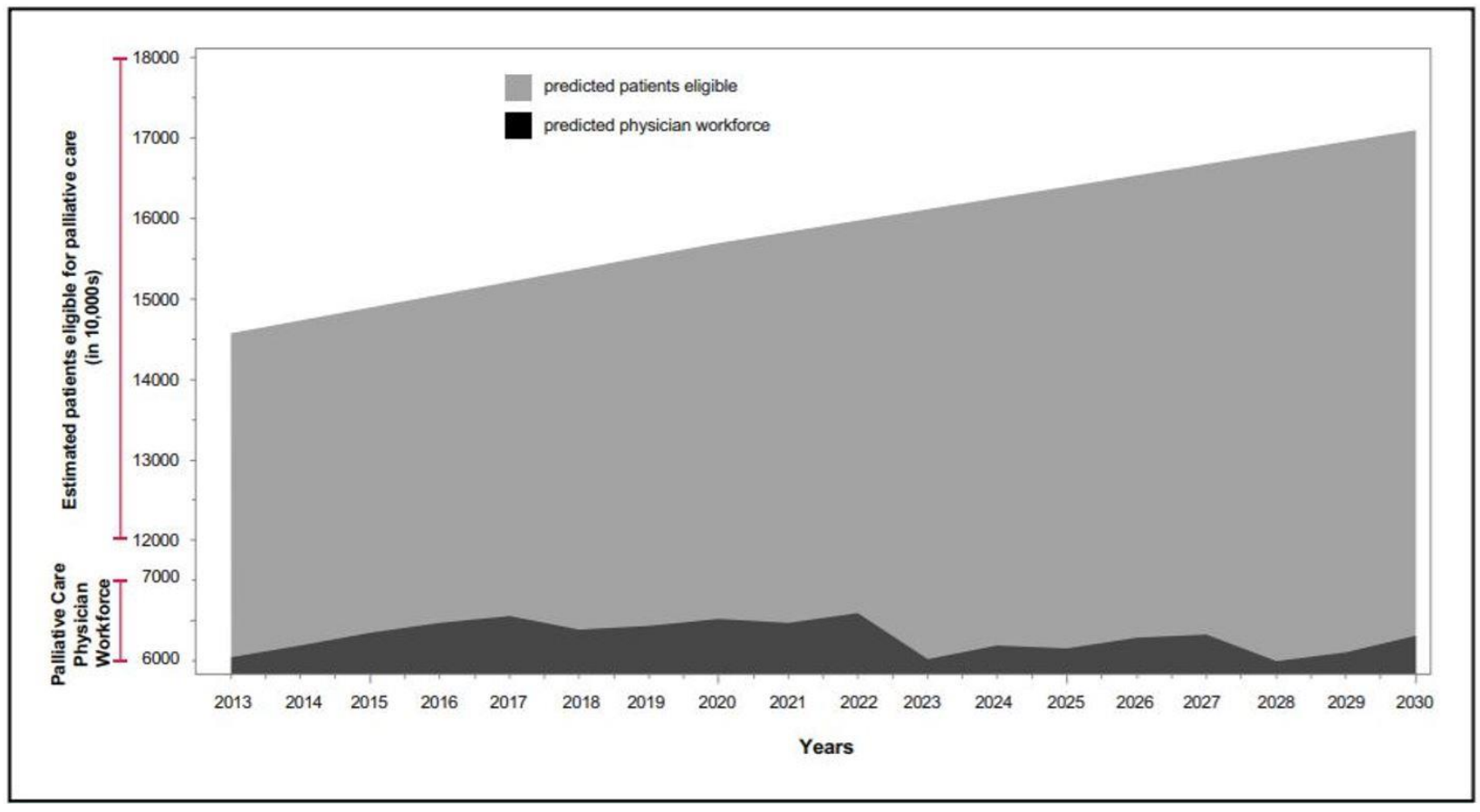




\section{Purpose of Study}

The purpose of this study is to gain insight into how technology can possibly assist informal caregivers with performing caregiving tasks for care recipients in addition to alleviating caregiver burden.

\section{Digital Health Technology}

Digital health technology is being deemed as a possible solution to assist caregivers with caring for elders whilst also managing care for themselves. Post COVID-19 pandemic, telehealth services have increased significantly as a viable technological method for delivering acute, chronic primary and specialty care. However, other technology possibilities do exist to potentially be a grave significance to caregivers while providing care and also managing their own care. For example, digital therapeutics allow health professionals to collect data for progress monitoring and preventive maintenance monitoring. Digital therapy treatments are being developed to assist with preventive maintenance of many chronic illnesses, such as diabetes, congestive heart failure, obesity, Alzheimer's, dementia, hypertension, anxiety, and depression.

Figure 4 Digital Health Technology Macrovector_official

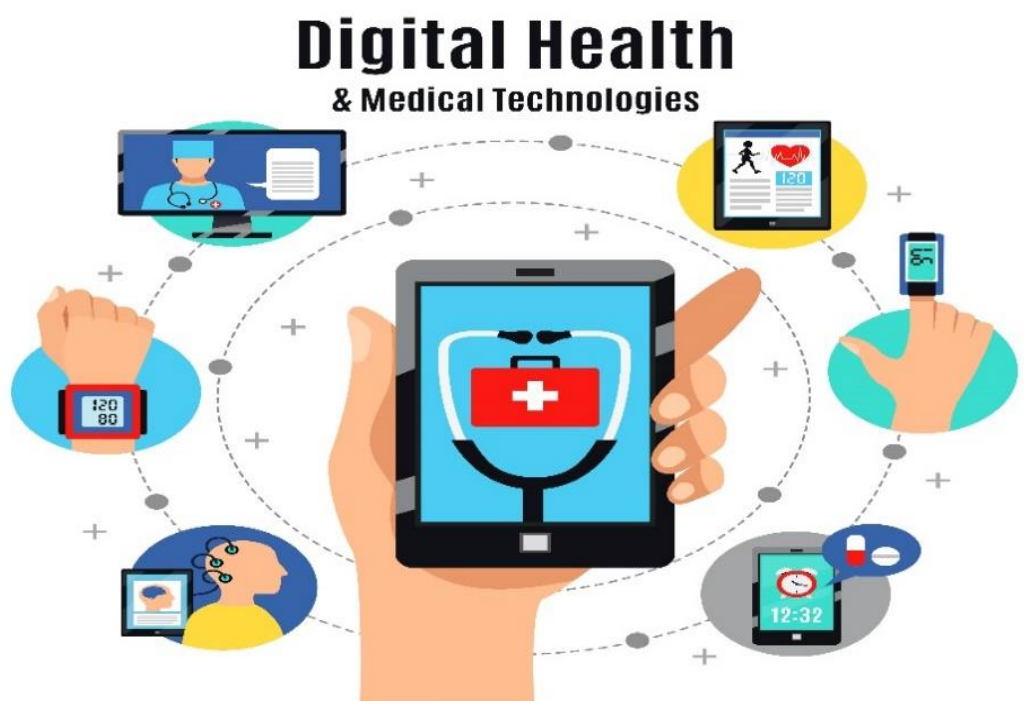

\section{Examples:}

- Mobile Apps (mHealth)

- HealthIT

- Digital Therapy

- Digital Education

- Digital Technology

- Wearable Devices

- Telehealth

- Telemedicine

- $\mathrm{AI} / \mathrm{ML}$ 
According to Semico (2013), "We want to grow old in our homes, surrounded by our families and living a normal life. Technology is how we can enable those 72 million people to accomplish this goal". Semico further states the aging in place market has huge potential growth for health vendors and wearable peripherals such as remote health monitoring hubs, oximeters, hearing aids, glucose monitors, medication reminders, scales, heart rate monitors, safety alert bracelets and smart patches can be beneficial to aging in place seniors. Wearable peripherals, also called wearable technology, are remote medical devices that can be used to monitor a patient's body signals by wearing a smart device allowing pertinent health data, such as heart rate, calories, blood pressure, and glucose levels, to be exchanged and monitored via health information exchange (Wikipedia, 2021). Diabetes technology has produced promising results for remotely monitoring diabetic patients with their glucose levels and insulin administration. These devices have been demonstrated to be clinically valuable, improving glycemic control and reducing risks of hypoglycemia in ambulatory patients with type 1 diabetes and type 2 diabetes. For example, Continuous Subcutaneous Insulin Infusion (CSII), a type of intensive insulin therapy, allows diabetic patients to wear an insulin pump and continually receive insulin injections as needed (American Diabetes Association, 2019). Remote Patient Monitoring (RPM) has proven beneficial with monitoring patients with chronic heart conditions. Per AHA, "RPM is a subset of telehealth that facilitates remote monitoring of patient's heart conditions such as hypertension, heart failure and atrial fibrillation, as well as the timely transfer of patientgenerated data from patient to care team and back to the patient. Research has shown RPM can reduce systolic blood pressure (SBP) and diastolic blood pressure (DBP) significantly compared to usual care and self-monitoring alone" (AHA, n.d.). Gaming Technology is another area of healthcare that has seen promising results with assisting caregivers and care recipients with pain management, rehabilitation, and digital therapeutics (Truong, 2019). According to NIA, "Because chronic conditions and medication requirements increase with age, older adults have a 
greater need for innovative approaches to self-care adherence. The scalable technology solutions currently on the market are not generally effective at engaging and motivating this population to improve adherence and clinical outcomes". The National Institute on Aging (NIA) office of Small Business Research has allocated funding for small businesses who strive to manufacture digital health and sensing technologies specifically for the aging population, in addition to developing products for Alzheimer's and Dementia related diseases (NIA, n.d.).

\section{Research Objectives}

1. Gain insight into the caregiver willingness to use technology to assist with caregiving needs.

2. Gain insight into the age group of caregivers who might be willing to use technology to assist with caregiving needs.

\section{Limitations}

Data to determine caregiver willingness to use technology was from 2020 data only. As technology usage and integration was a new added part of the 2020 survey, prior years did not include this information, so no other data is available to be used for comparison 


\section{Definition of Terms}

Digital Health - Digital technologies with health, healthcare and living to enhance efficiency of healthcare delivery.

Digital Medicine - Subset of digital health that encompasses administration of pharmaceuticals through communication with mobile and/or web-based applications.

Digital Therapeutics - Subset of digital health that encompasses therapeutics interventions administered through high powered software to prevent, manage, or treat a medical disorder.

eHealth - Healthcare services provided electronically through the internet

ICT - Information and communication technology is used to assist healthcare professionals in the diagnosis, treatment, monitoring, medical prescribing, referral, information retrieval and communication, documentation, and transactions of patient care.

mHealth - Mobile health, used to describe medical services provided and supported through mobile devices.

RPM - Remote Patient Monitoring is a technology to enable monitoring of patients outside of conventional clinical settings, such as in the home or in a remote area, which may increase access to care and decrease healthcare delivery costs.

Telehealth - the use of electronic information and telecommunications technologies to support long-distance clinical health care, patient and professional health-related education, public health, and health administration

Wearables - electronic devices that individuals can wear and are designed to collect data and vital statistics regarding the individual's health. 


\section{Chapter 2 - Review of Literature}

A literature review was performed to research topic relevancy and to identify any research already performed on the subject of informal caregivers and their use of technology to alleviate caregiver burden. The methods used to research, and the findings are presented here.

\section{Inclusion and Exclusion Criteria}

A literature review was performed using PubMed/Medline, and CINAHL databases. The research was conducted using combinations of key words "caregiver", "burden", and "technology". The research was limited to journal articles published during the years 2017 to 2021 to ensure technological relevancy. To further narrow the results, only papers of full text and free full text articles were included. Additionally, subjects were limited to human. Lastly, studies done outside of the United States were excluded from the search and only articles with the language of English were included.

\section{Results}

The search method identified a total of 226 articles, 191 from PubMed/Medline and 35 from CINAHL. The 226 articles were further reviewed by title and abstract text. After further review, 188 additional articles were excluded from the original search results, 168 from PubMed/Medline and 20 from CINAHL resulting in 38 articles remaining. Article eligibility was implemented and after review of the article full text, 5 additional articles were removed from PubMed/Medline and 5 were removed from CINAHL search results. The total number of articles to be utilized for the literature review was 28 . 
Figure 5 Literature Review Diagram

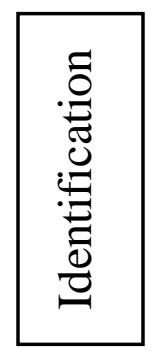

Articles identified through database searching

- PubMed/Medline $=191$

- CINAHL $=35$

$$
(\mathrm{n}=226)
$$

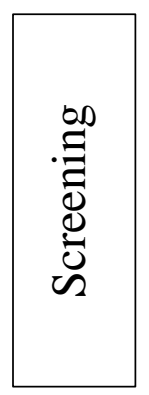

\begin{tabular}{c|c|c|}
$\begin{array}{c}\text { Records screened } \\
\text { for title and abstract } \\
(\mathrm{n}=226)\end{array}$ & $\begin{array}{c}\text { Articles excluded based on title } \\
\text { and abstract }\end{array}$ \\
- PubMed/Medline $=168$ \\
CINAHL $=20$ \\
$(\mathrm{n}=188)$
\end{tabular}
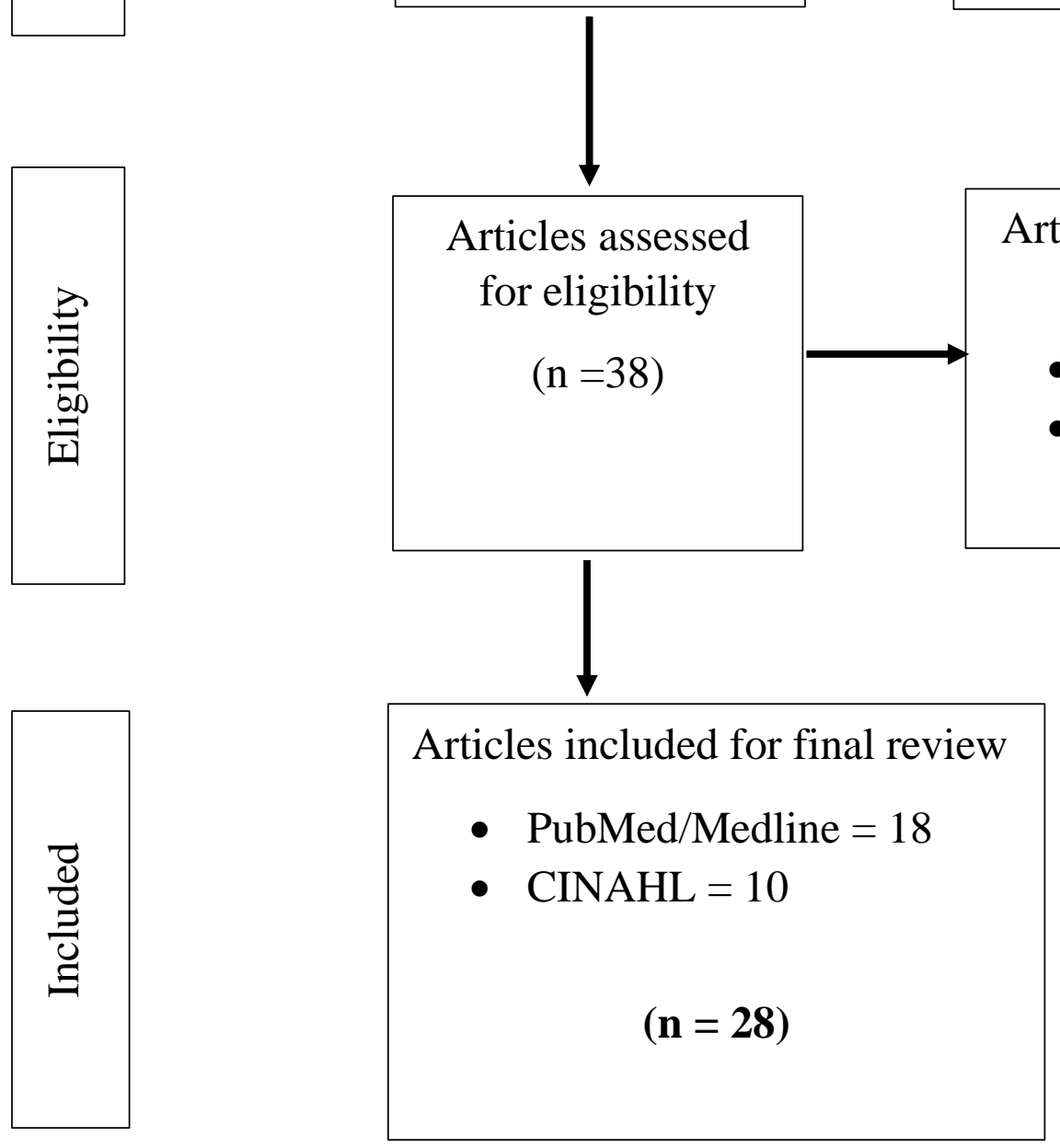


\section{Populations Studied}

The literature reviewed included studies on caregivers and their care recipients. The studies also focused on caregivers and care receivers who could potentially benefit from using some type of digital health to assist with caregiving tasks. Many of the elderly care recipients in the study had at least one chronic illness. Sixteen studies highlighted care recipients who suffered from Alzheimer's or Dementia. Three studies focused on care recipients who had cancer. One study focused on a care recipient who had diabetes. Lastly, eight studies focused on elderly care recipients who had no chronic illnesses.

Figure 6 Literature Review By Care Recipient Illness

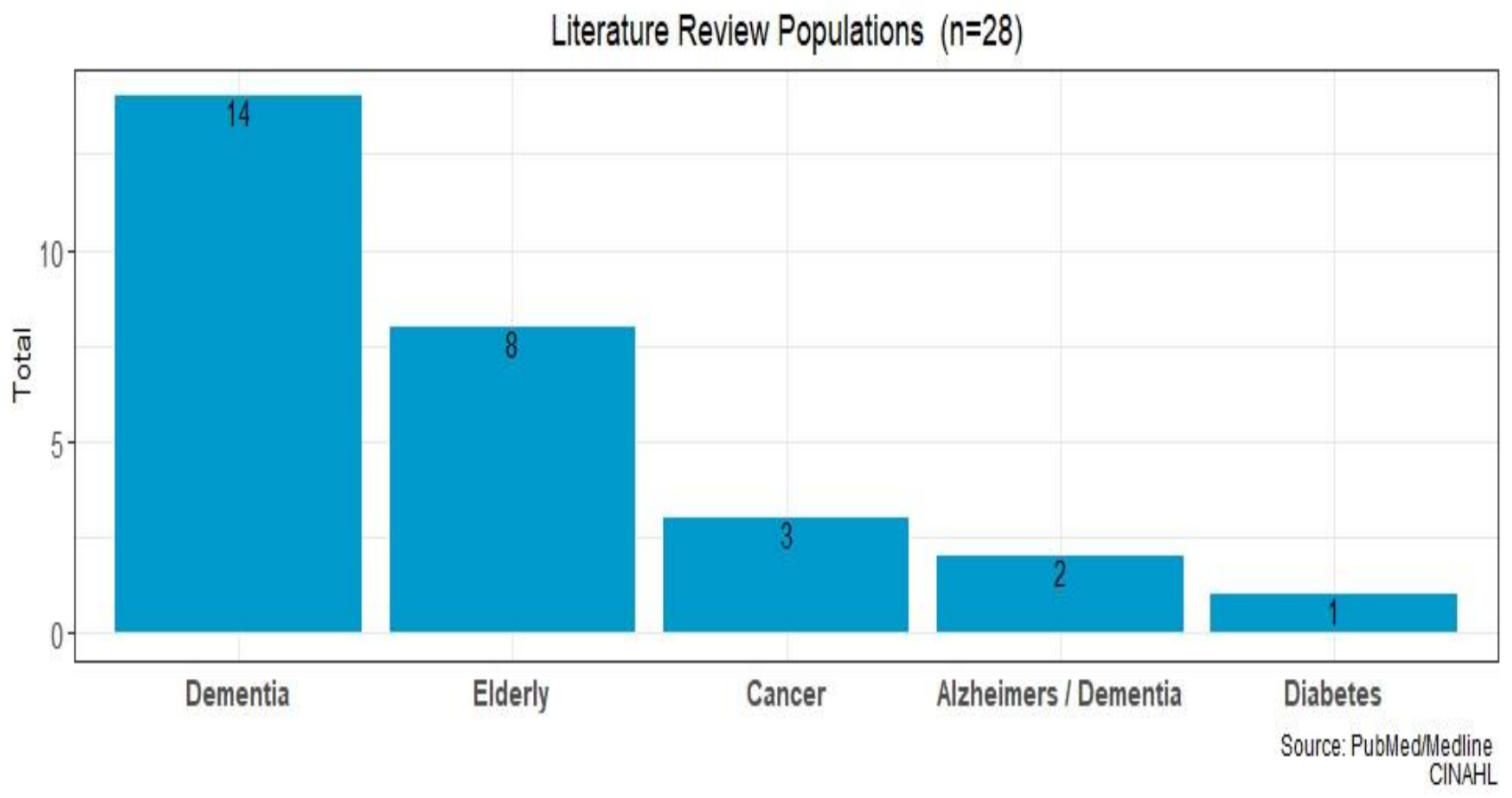




\section{Findings}

Innovations of implementing digital health into the elderly and caregiving spectrum appears to be highly receptive by caregivers given they feel comfortable using the tools. However, barriers still exist in making sure caregivers are trained in how to utilize the technological tools.

Figure 7 Literature Review by Technologies Included

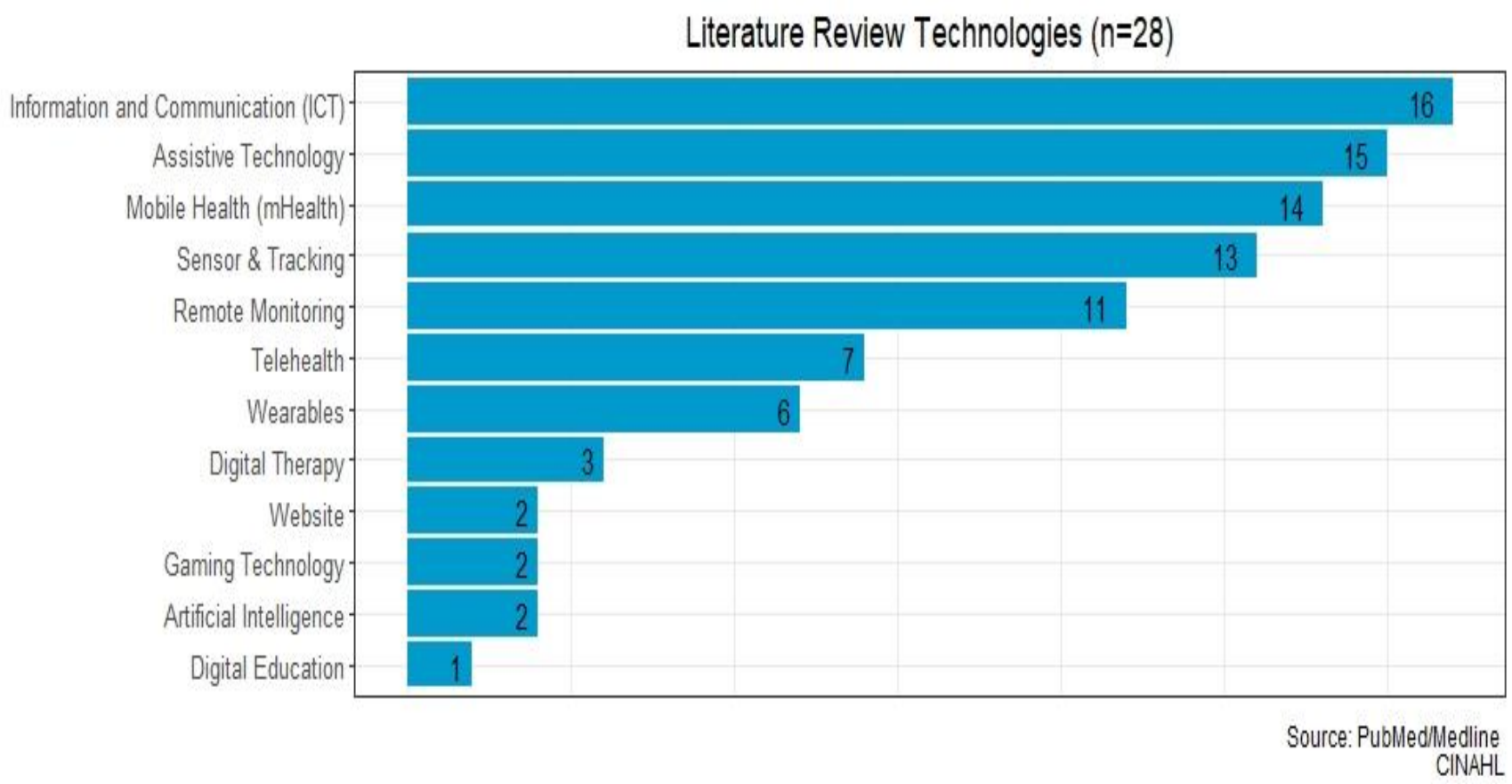

\section{Limitations}

1. Each caregiver had varying tasks and duties based off their care recipient needs.

2. The technical skill set of the caregivers and care recipients per each article varied.

\section{Conclusion}

The results indicated that digital health can be extremely assistive to caregiver; however, must research and development is still needed in order to ensure the caregiver needs are understood. 


\section{Chapter 3- Methodology}

This study was granted approval by the University of Tennessee Health Science Center's (UTHSCs) Institutional Review Board (IRB). No consent was required as all data was open source deidentified data.

\section{Research Design}

A descriptive qualitative methodology was implemented to conduct the research study. Secondary sources were used to collect, mine and analyze the data. Open datasets from the Centers for Medicare and Medicaid Services (CMS), the American Association of Retired People (AARP) and Caregiving.org were utilized as well as national caregiving survey data from published research report Caring in the US 2020. The research for the national caregiving survey was conducted by AARP Family Caregiving and National Alliance for Caregiving (NAC) during the timeframe of May 28 to July 27, 2019. The survey results were published in 2020.

\section{Population}

The survey was administered online nationally and through the telephone to a population of 7309 potential caregivers with a demographic consisting of samples from the general national population as well as targeted samples of African Americans, Hispanics, and Asians. Of the 7309 identified in the base study, 5810 were identified as no caregivers or caregivers with incomplete surveys. Additional oversample surveys were conducted to strengthen the validity of the survey. After further review and analysis, 1392 individuals were finally selected and validated as qualitied caregiver respondents eligible to participate in the national survey.

\section{Data Analysis}

$\mathrm{R}$ programming language was utilized to perform data mining, data aggregation and data visualization of the survey data. 


\section{Chapter 4 - Results}

This chapter will describe the response rate from the surveyed caregiving population regarding their caregiving tasks and the integration of technology to perform such tasks.

\section{Care Recipient Age vs Caregiver Age}

The comparison was made between the age demographics of the caregivers and care recipients. The age groups were categorized as 18 to 34,35 to 49,50 to 64,65 to 74 and $75+$. The age group with the highest number of caregivers was between the ages range of 50 to 64 . The age group with the highest number of care recipients were aged 75 years and older. It is important to note the average age of caregivers per the surveyed population was 49.4 years of age.

Figure 8

Care Recipient vs Caregiver By Age

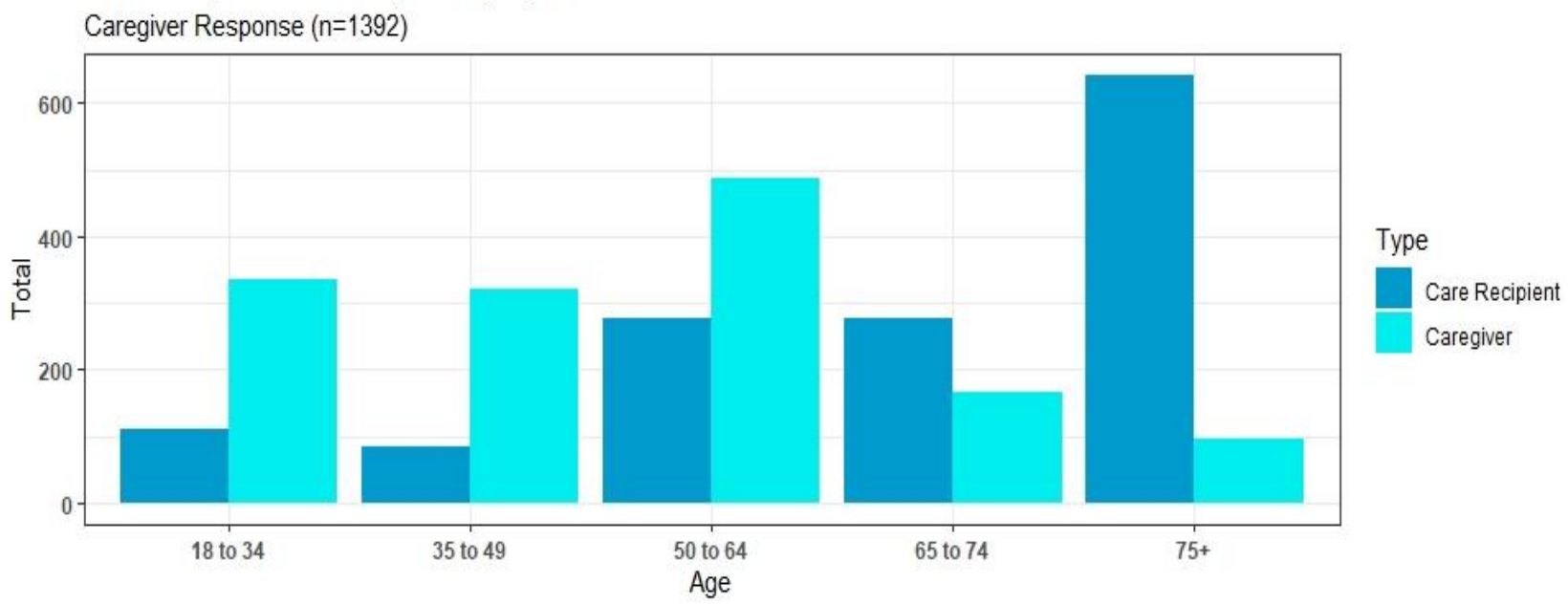

\section{ADL vs IADL}

The types of IADL and ADL services performed by the caregivers were identified. According to the results, the IADL more complex services were performed the most by caregivers in relation to basic ADL services. 
Figure 9

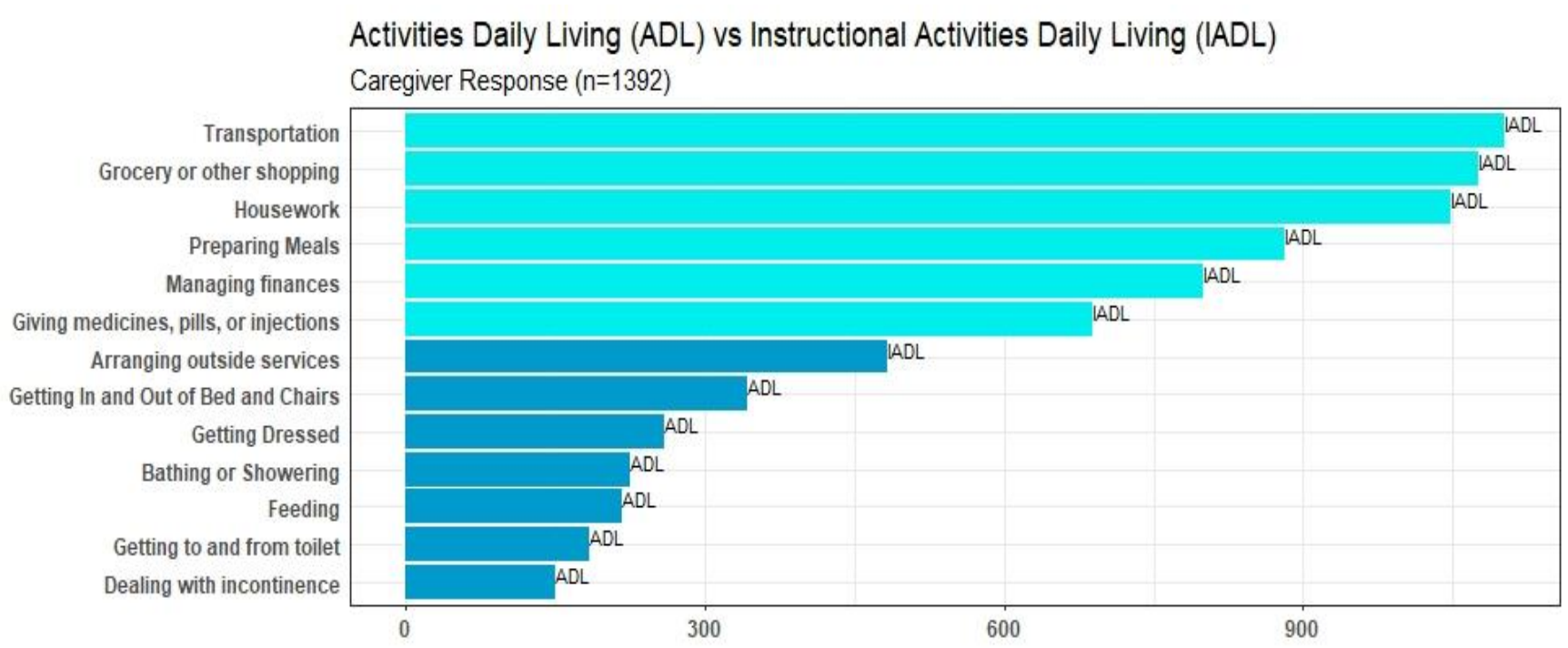

\section{Main Problem or Illness By Care Recipient}

Caregivers were asked to select the illnesses that best represented the care recipient they were caring for. Based off their responses, the caregivers indicated their care recipients primarily suffered from old age.

Figure 10

Main Problem or Illness by Care Recipient Age 65+

Caregiver Response $(n=944)$

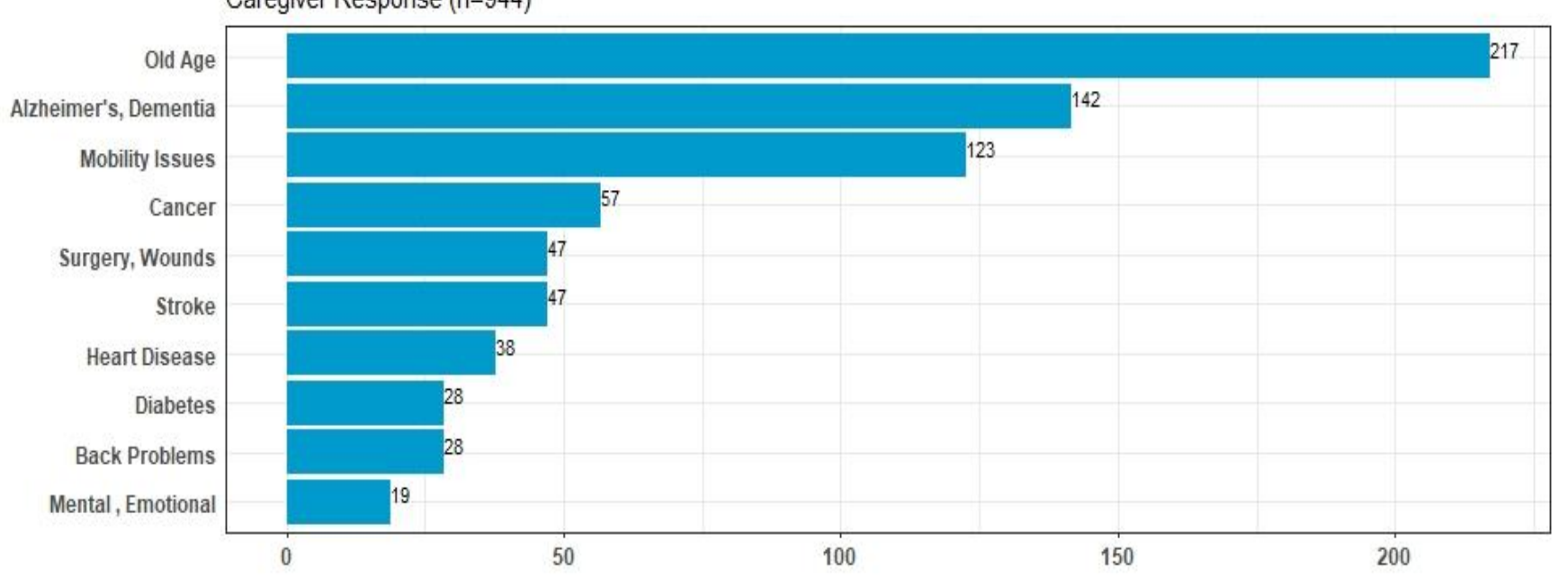


The 2020 national caregiving survey marks the first-year caregivers were asked about their usage of technology to perform caregiving tasks.

\section{Use of Software and Monitoring Technology}

The top software and monitoring caregiving task performed using technology was tracking care recipient's finances. The second caregiving task performed the most using software and monitoring technology was to track the care recipient's personal health records.

Figure 11

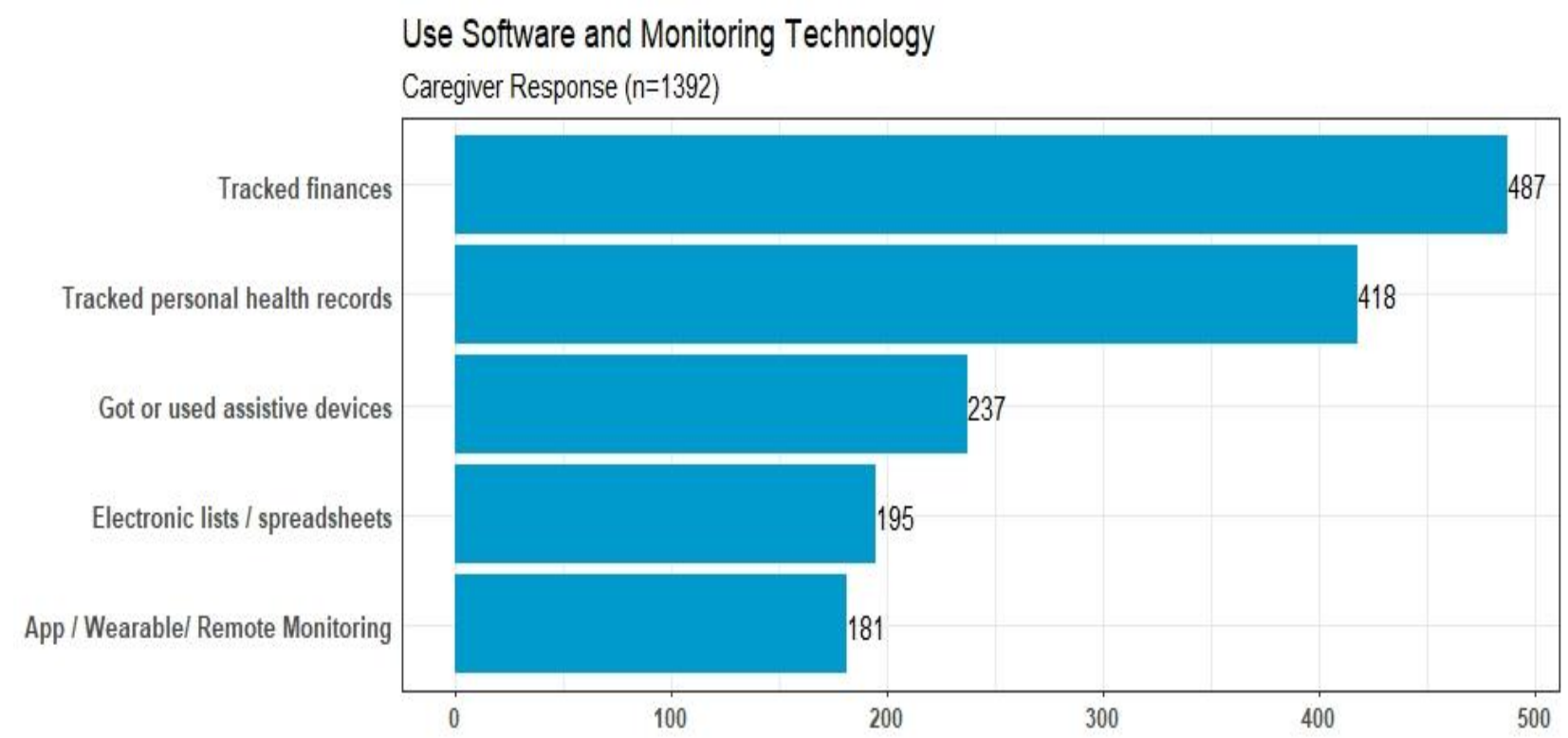

\section{Use of Online Solutions Technology}

The top online solutions caregiving task performed using technology was searching the internet for support services. The second caregiving task performed using online solutions technology was to refill prescriptions. Surprisingly, virtual or online visits with health care provider ranked last; however, the survey was conducted pre COVID-19. 
Figure 12

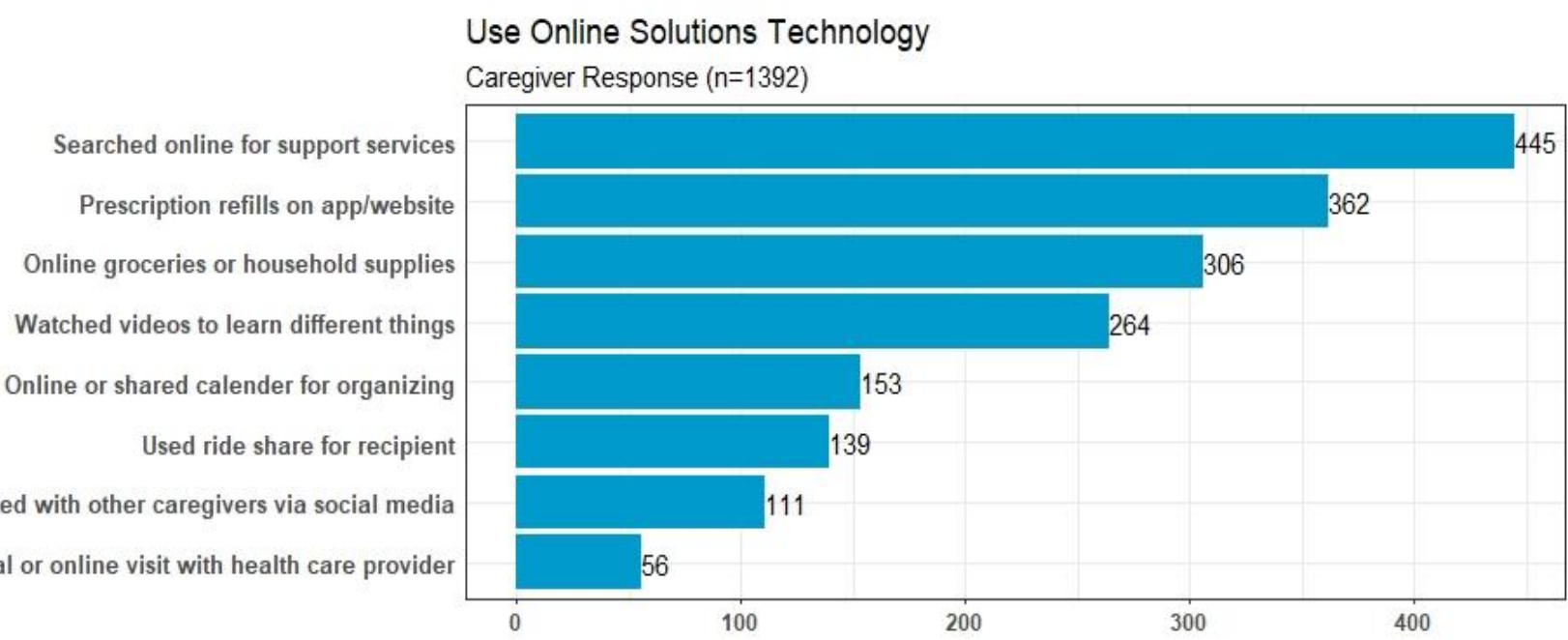

\section{Technology Usage by Age}

Software monitoring and online solutions technology tasks were combined, and survey respondents were analyzed according to their age and their usage of technology to perform caregiving tasks. Results show caregivers who fall in the 65 and older age group were least likely to utilize technology. However, caregivers who fall within the age groups 18 to 49 and 18 to 64 were most likely to utilize technology to assist with caregiving tasks.

Figure 13

Online and Software Monitoring Technology Usage By Age

Caregiver Response $(n=1392)$

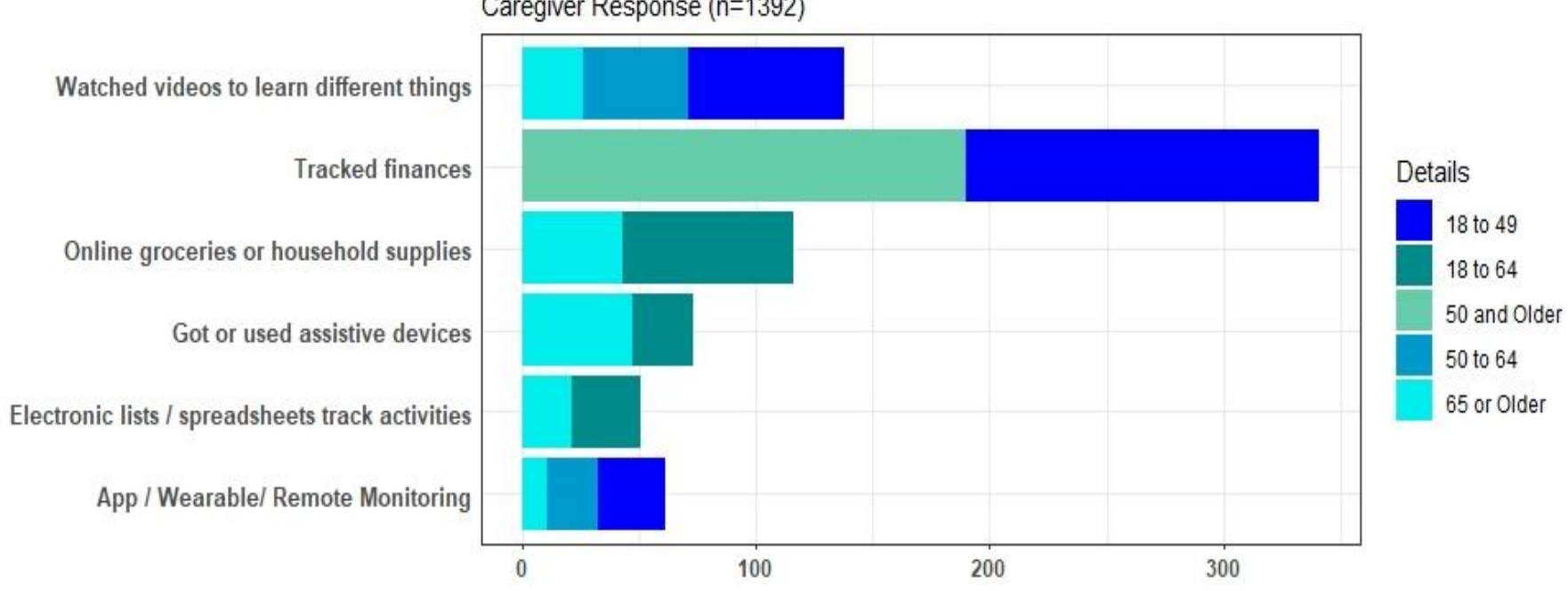




\section{Chapter 5 - Conclusions}

Per the caregiving survey results, caregivers perform significant ADL and IADL tasks for care recipients. The results further substantiate integration of technology into caregiving tasks can be both beneficial for the care recipient and the caregiver. As we continue to provide support to our aging baby boomers, technology leverage will be essential to delivering quality LTSS care whilst providing a supportive infrastructure for our informal caregivers. Digital health technology has a projected compounded annual growth rate from 2020 to 2027 of 16.5 percent reaching $\$ 551$ billion dollars, signifying technology as a major component with optimum and innovative healthcare delivery (Precedence Research, 2021).

\section{Implications of the Study}

The implications of this study are significant for both our formal and informal caregivers, healthcare professionals and healthcare entities. Understanding how to utilize and integrate digital health technology to leverage the workload allows healthcare professionals to perform their tasks more efficiently and effectively by working smarter and not harder. Additionally, it allows healthcare entities to restructure and reimagine delivery of innovative healthcare. Lastly, as digital health benefits are more realized, newer policies can be enacted to fully support and embrace digital health technology as a newer, more robust delivery of healthcare.

\section{Recommendations}

Because the year 2020 was the first year caregivers were asked questions regarding their use of technology while caring for care recipients, final recommendations are to continue to monitor caregivers and their integrated use of technology into their caregiving tasks. Additionally, monitoring caregivers for development of chronic conditions while caring for care recipients to determine if caregiving duties actually contributes to a caregiver's illness of becoming a secondary patient. 


\section{References}

AHA. (n.d.) Using Remote Patient Monitoring Technologies for Better Cardiovascular Disease Outcomes Guidance. Retrieved from https://www.heart.org/-/media/files/about-us/policy$\underline{\text { research/policy-positions/clinical-care/remote-patient-monitoring-guidance-2019.pdf }}$

AHRQ. (2017, July). Physician Burnout. Retrieved from

https://www.ahrq.gov/prevention/clinician/ahrq-works/burnout/index.html

Allen, K. (2017, October 9). Family Caregivers Overwhelmed and Undertrained. Retrieved from https://www.aarp.org/caregiving/life-balance/info-2017/caregiver-stress-statistics-fd.html

American Diabetes Association. (2019 Jan). Diabetes Technology: Standards of Medical Care in Diabetes. Diabetes Care. 42(Supplement 1): S71-S80. https://doi.org/10.2337/dc19-S007

APA. (2020, June). Coping with Caregiving Stress and Burden. Retrieved from

https://www.apa.org/pi/about/publications/caregivers/practicesettings/assessment/tools/stress-burden

Barnett, R. (2017, April 27). The puzzle of aging: Elizabeth Blackburn speaks at TED2017. Retrieved from https://blog.ted.com/the-puzzle-of-aging-elizabeth-blackburn-speaks-at$\underline{\text { ted } 2017 /}$

CDC.gov. (2009a, October 15). Healthy Places Terminology. Retrieved from https://www.cdc.gov/healthyplaces/terminology.htm

CDC.gov. (2019b, November 25). Caregiving Retrieved from https://www.cdc.gov/aging/caregiving/index.htm 
CMS.gov, (2018a, December 6). CMS Office of the Actuary Releases 2017 National Health Expenditures. Retrieved from https://www.cms.gov/newsroom/press-releases/cms-officeactuary-releases-2017-national-health-expenditures

CMS.gov. (2021b, January 15). Chronic Conditions. Retrieved from https://www.cms.gov/Research-Statistics-Data-and-Systems/Statistics-Trends-and$\underline{\text { Reports/Chronic-Conditions/CC_Main }}$

Damjanovic, A. K., Yang, Y., Glaser, R., Kiecolt-Glaser, J. K., Nguyen, H., Laskowski, B., Zou, Y., Beversdorf, D. Q., \& Weng, N. P. (2007). Accelerated telomere erosion is associated with a declining immune function of caregivers of Alzheimer's disease patients. Journal of immunology (Baltimore, Md. : 1950), 179(6), 4249-4254. https://doi.org/10.4049/jimmunol.179.6.4249

Feinberg, L. (2019, March 11). Strengthening the National Family Caregiver Support Program: The Time Has Come. Retrieved from https://blog.aarp.org/thinking-policy/strengtheningthe-national-family-caregiver-support-program-the-time-has-come

FPAnalytics, AARP. (2019). The Aging Readiness and Competitiveness Report. Retrieved from https://arc.aarpinternational.org/File\%20Library/Full\%20Reports/ARC-Report---United$\underline{\text { States.pdf }}$

Getpalliativecare.org. (2021). What is Palliative Care? Retrieved from https://getpalliativecare.org/whatis/

Gratão, A., Brigola, A. G., Ottaviani, A. C., Luchesi, B. M., Souza, É. N., Rossetti, E. S., de Oliveira, N. A., Terassi, M., \& Pavarini, S. (2019). Brief version of Zarit Burden Interview (ZBI) for burden assessment in older caregivers. Dementia \& neuropsychologia, 13(1), 122-129. https://doi.org/10.1590/1980-57642018dn13-010015 
Heath, S. (2020, May 4). Chronic Care Must Account for SDOH Needs, Family Caregivers. Retrieved from https://patientengagementhit.com/news/chronic-care-must-account-for$\underline{\text { sdoh-needs-family-caregivers }}$

Kamil, A., Bull, J., Swetz, K., Wolf, S., Shanafelt, T., \& Myers, E. (2017, February). Future of the Palliative Care Workforce: Preview to an Impending Crisis. The American Journal of Medicine, 130(2),113-114. https://doi.org/10.1016/j.amjmed.2016.08.046

Kelly, K., Wolfe, N., Gibson, M, \& Feinberg, L. (2013, December). Listening to Family Caregivers: The Need to Include Family Caregiver Assessment in Medicaid Home- and Community-Based Service Waiver Programs. Retrieved from https://www.aarp.org/content/dam/aarp/research/public_policy_institute/ltc/2013/theneed-to-include-family-caregiver-assessment-medicaid-hcbs-waiver-programs-report$\underline{\text { AARP-ppi-ltc.pdf }}$

Liu, Z., Heffernan, C., \& Tan, J. (2020). Caregiver burden: A concept analysis. International journal of nursing sciences, 7(4), 438-445. https://doi.org/10.1016/j.ijnss.2020.07.012

Macrovector_official. (n.d.) Digital Health. Retrieved from https://www.freepik.com/freevector/digital-health-technologies-flatcomposition 7272631.htm\#page=1\&query=digital\%20health\&position=1

Mate, Gabor. (2013, March 6). Self Care for Caregivers: When The Body Says No - Caring for ourselves while caring for others. Retrieved from https://www.youtube.com/watch?v=c6IL8WVyMMs

NAC, AARP.(2020). Caregiving in the US 2020. Retrieved from https://www.caregiving.org/wp-content/uploads/2021/01/full-report-caregiving-in-the$\underline{\text { united-states-01-21.pdf }}$ 
NIA. (n.d.) Digital Health and Sensing Technologies. Retrieved from https://www.nia.nih.gov/research/osbr/nia-small-business-showcase/digital-health$\underline{\text { sensing-technologies }}$

Precedence Research. (2021, June 30). Digital Health Market Size to Garner Around US\$ 551.1 Bn by 2027. Retrieved from https://www.globenewswire.com/newsrelease/2021/06/30/2255806/0/en/Digital-Health-Market-Size-to-Garner-Around-US551-1-Bn-by-2027.html

Redfoot, D., Feinberg, L., \& Houser, Ari. (2013, August). The Aging of the Baby Boom and the Growing Care Gap: A Look at Future Declines in the Availability of Family Caregivers. Retrieved from https://www.aarp.org/home-family/caregiving/info-08-2013/the-aging-ofthe-baby-boom-and-the-growing-care-gap-AARP-ppi-ltc.html

Reinhard, S., Feinberg, L., Houser, A., Choula, R., Evans, M. (2019, November 14). Valuing the Invaluable 2019 Update: Charting a Path Forward. Retrieved from https://www.aarp.org/ppi/info-2015/valuing-the-invaluable-2015-update.html

Roberts, A., Ogunwole, S., Blakeslee, L, \& Rabe, M. (2018, October). The Population 65 Years and Older in the United States: 2016: American Community Survey Reports. Retrieved from https://www.census.gov/content/dam/Census/library/publications/2018/acs/ACS$\underline{38 . p d f}$

Semico.(2013, July). Aging In Place The Internet of Things for the Golden Years. Retrieved from https://semico.com/sites/default/files/TOC_MP104-13.pdf

Slaboda, J., Nelson, S., Agha, Z., \& Norman, G. (2021). A national survey of caregiver's own experiences and perceptions of U.S. health care system when addressing their health and 
caring for an older adult. BMC Health Serv Res 21, 101 (2021).

https://doi.org/10.1186/s12913-021-06086-z

Spigelmeyer, P. (2019, January 18). Don't Forget to Assess the Family Caregiver of Your Older Adult Patient. Retrieved from https://www.hcplive.com/view/dont-forget-assess-family$\underline{\text { caregiver-older-adult-patient }}$

Truong, K. (2019, May 19). Playing doctor: The evolution of videogames in healthcare.

Retrieved from https://medcitynews.com/2019/05/from-joke-hour-to-digital-therapeuticsan-evolution-of-gaming-in-healthcare/

Turnage, D. (nd). Social Determinants of Caregiver Health: Implications for Practice, Policy, and Research. Retrieved from https://sigma.nursingrepository.org/bitstream/handle/10755/16547/Turnage_PST183_935 01.pdf? sequence $=1 \&$ isAllowed $=y$

Wikipedia. (2021, August 10). Wearable Technology. Retrieved from https://en.wikipedia.org/wiki/Wearable technology

Young, H. M., Bell, J. F., Whitney, R. L., Ridberg, R. A., Reed, S. C., \& Vitaliano, P. P. (2020). Social Determinants of Health: Underreported Heterogeneity in Systematic Reviews of Caregiver Interventions. The Gerontologist, 60(Suppl 1), S14-S28.

https://doi.org/10.1093/geront/gnz148 